\title{
A 10-year Prospective Study of Mortality among Norwegian Drug Abusers after Seeking Treatment
}

\section{Edle Ravndal ${ }^{1 *}$, Grethe Lauritzen ${ }^{2}$ and Michael Gossop ${ }^{3}$}

${ }^{1}$ University of Oslo, Norwegian Centre for Addiction Research (SERAF), Ullevål Hospital, 0315 Oslo, Norway

${ }^{2}$ Norwegian Institute for Alcohol and Drug Research (SIRUS), Øvre Slottsgt. 2B, 0157 Oslo, Norway

${ }^{3}$ National Addiction Centre, National Addiction Centre, 4 Windsor Walk, London SE5 8BB, UK

"Corresponding author: Edle Ravndal, University of Oslo, Norwegian Centre for Addiction Research (SERAF), P.O. Box 1039 Blindern, 0315 Oslo, Norway, Tel: 4723 3689 74; Fax: 47233689 86; E-mail: edle.ravndal@medisin.uio.no

Received date: Feb 26, 2015; Accepted date: Mar 20, 2015; Published date: Mar 25, 2015

Copyright: (C) 2015 Ravndal E, et al. This is an open-access article distributed under the terms of the Creative Commons Attribution License, which permits unrestricted use, distribution, and reproduction in any medium, provided the original author and source are credited.

\begin{abstract}
Background: Injecting drug users have a mortality risk between 10 and 20 times higher than the general population, and the persistent high mortality rate in most Western countries, and especially in Norway, is a major public health concern. Naturalistic, prospective studies following drug abusers over many years are needed in order to investigate the most important predictors of mortality and for planning strategic preventive measures.

Methods: Four hundred and eighty-one drug abusers were followed prospectively for 10 years after admission to treatment during the period 1998-2009. Following instruments were used: the European Addiction Severity Index, Symptom Checklist-25 and Millon Clinical Multiaxial Inventory-II. Information on deaths and causes of death were obtained from the National Death Register. Cox regression analysis was used to analyze factors hypothesized to be associated with the risk of death.
\end{abstract}

Results: A total of 74 deaths were registered during the observation period, which represents a mortality rate of 1.5 per 100 person-years. The main cause of death was overdose, and the relative risk of mortality among males was twice that of females.

Conclusions: Fifteen percent of the drug users in the study died during the 10 years after admission to index treatment. This represents an annual mortality rate of 1.5; which is in line with most similar studies from Europe, showing a mortality rates in the range of $1-2 \%$ per year. The main cause of death was overdose (68\%). Preventive strategies aiming to reduce mortality among drug users have to be manifold and gender specific, taking into account drug abusers' life conditions, their modes of thought and how they go about living their lives.

\section{Keywords: Drug abuse; Mortality; Overdoses; Treatment;} Prospective

\section{Introduction}

There is a high mortality rate among drug abusers, and death by overdose is the most common cause of death [1-4]. In general, just being a drug abuser, and especially being a heroin injector, increases the risk of early death. Users who inject drugs have a mortality risk between 10 and 20 times higher than the general population [5]. The persistent high annual mortality rate among drug abusers in most Western countries is a major public health concern.

Men who have injected drugs over many years are at particularly increased risk of dying from overdoses of injected heroin, most often in combination with other substances such as benzodiazepines and alcohol $[4,6,7]$. Those who die of an overdose have often had previous nonfatal overdoses $[2,8,9]$, and the majority of these deaths occur at a residential address $[4,10,11]$. Also, releases from prison, or in- and outpatient treatment, are particularly critical periods [3,10,12-15], mainly because of injecting heroin when tolerance from opiate use is reduced. Altogether, death by overdose is caused by a complex interplay between several factors, and an essential task is to try to target these factors with preventive measures $[4,10,16,17]$.

Compared to international statistics, Norway ranks low in the number of people who have tried illegal drugs, but high (relatively) in per capita drug related deaths [5]. The peak year was in 2001 with 405 registered deaths (The WHO ICD coding system versions 9 (code 304) and 10 (a combination of F, X and T codes were used in accordance with the EMCDDA standard protocol for unintentional death) defined these figures), followed by a drop in 2003 (255 deaths) and a more or less stable situation up till 2013 [18]. Opiate maintenance treatment (OMT), which was introduced nationally in Norway in 1998, and other measures to establish low thresholds facilities, seem to have reduced mortality, but still remains a matter of national concern [2].

Prospective studies conducted over longer time periods to investigate factors associated with mortality are rare. Such studies are difficult to implement and costly in terms of finances and other resources required. This paper presents a naturalistic, prospective study of 481 drug abusers, entering 20 different in- and outpatient treatment facilities in Norway, and followed for 10 years. Given the high death rate among drug abusers in Norway we expected that the death rate would be higher in this treatment cohort than in similar 
populations internationally. On the other hand research also shows that being in treatment protects from drug related deaths $[1,3]$. However, during a 10-year observation period, one would expect that a considerable percentage of the sample would drop out from treatment and start new treatment episodes in other programs, thus increasing the numbers of dropouts and at the same time increasing the risk for overdoses $[3,13]$. During a 10 -year period, some would also finish serving their sentences, leave prison and be in great danger of overdose death $[14,19,20]$.

Although several studies have been conducted to identify factors associated with drug related deaths $[1,4,15]$, Degenhardt et al. [1] suggest that mortality among opioid dependent users may vary across countries, populations and time periods. To improve prevention of drug related mortality, more knowledge of different drug abuse populations in different countries and cultures is necessary, following cohorts of drug abusers over years and in new time periods.

The aim of this study was to investigate the following questions: 1) What was the mortality rate in a cohort of treatment-seeking drug abusers during a 10-year period (1998-2009) including the time spent in index treatment? 2) What were the main causes of death? 3) To what extent were patient characteristics and time in index treatment associated with increased risk of death by overdose and of death by other causes?

\section{Methods}

\section{Design and study setting}

The study is a prospective, naturalistic study of 481 substance abusers who consecutively entered 13 inpatient $(n=307)$ and 7 outpatient $(n=174)$ programs in Oslo and surrounding counties between January 1998 and August 2000. The programs were purposely chosen to provide a sample of the most widely used treatment programs in Norway at the time. Additionally, the programs were chosen for practical reasons, thus excluding similar treatment programs situated in regions far away from Oslo. The majority of these programs worked for the intention for patients to stay for extended periods of time. In 1998 the first national treatment program for Opiate Maintenance Treatment (OMT) started and also this program was included in the study.

\section{Participants, recruitment and procedures}

Participation in the study was voluntary. Few of the residential patients refrained from participating $(n=12)$. It was more difficult to engage all potentially eligible outpatients in the study, mostly due to drop out from treatment after the first sessions. However, these patients did not differ significantly from the rest in terms of background characteristics (21). Participants were recruited from two types of inpatients and two types of outpatient programs, including both adults and younger patients.

All patients were assessed during the first two weeks of the index treatment. They were interviewed and rated, using the European Addiction Severity Index (EuropASI) [22]. Participants also completed two self-report questionnaires: the Symptom Checklist 25 (HSCL-25) [23] and the Millon Clinical Multiaxial Inventory II (MCMI II) [24].

The EuropASI is a personal, structured interview that covers seven areas: medical status, employment and support status, drug and alcohol use, legal status, family history, family and social relationships and psychiatric status $[22,25]$. Further questions were added that were specific to the Norwegian social security system, with detailed questions about earlier in- and outpatient treatment, questions about children and child-care arrangements, learning and/or behavioural problems in primary school and contact with the child welfare services. At baseline staff in eleven treatment programmes interviewed all new patients, while the researchers (ER and GL) interviewed the rest of the sample $(n=231)$. All follow-up interviews were performed by ER and GL and by specially trained interviewers (social workers and master students). All interviewers were trained at an authorised EuropASI course.

The HSCL-25 is a 25-item self-report inventory, assessing symptoms of depression and anxiety [23]. The mean overall score, the General Symptom Index (GSI) measures total symptom score in the week prior to the interview. Clients with mean score of 1.0 and above are considered "cases". In the analyses the depression and anxiety scores were used as well as the GSI index.

The MCMI II is a self-report instrument with 175 true/false items measuring 13 personality profiles and nine clinical syndromes according to the DSM-III-R system [24]. Scores on MCMI are reported as Base Rate (BR) scores that are transformed raw scores adjusted for gender differences. According to international practise, patients who score 85 and above are considered to have a Personality Disorder (PD).

\section{National death register}

Information on deaths and causes of death (ICD coded) was obtained from the National Death Register kept by Statistics Norway (SSB, 2013). Inclusion of deaths in the "overdose" category is based on ICD codes F11 and X42 with opioid use as the main cause of death.

\section{Statistical analyses}

Mortality rate was calculated by the number of deaths divided by the number of 100 person years at risk. Categorical variables were analysed using chi-square and t-tests were employed for continuous variables. Highly skewed continuous data were analysed using the Mann-Whitney $U$ statistic, a non-parametric analogue of the t-test. Because of quite skewed variables bivariate relationships were examined with Spearman's rho. First differences in background variables before index treatment were tested between the deceased and non-deceased group of clients. Then Cox regression analysis was used to analyse factors hypothesized to be associated with the risk of death. Statistics were performed by SPSS version 19.0.

\section{Ethics}

This study was approved by the Norwegian Medical Ethics committee and the Norwegian Data Inspectorate.

\section{Results}

\section{Deceased patients}

A total of 74 deaths (15\%) were registered among the 481 study participants during the ten-year observation period. Ten of these were females and 64 were men. This represents a mortality rate of 1.5 per 100 person-years, 2.0 for males and 0.6 for females. 
Page 3 of 6

The mean (and median) age at baseline for deceased patients was 32 years (range: 14-52, $\mathrm{SD}=8.1$ ), 32 years for males and 29 years for females (ns) (Table 1). Mean age at death was 36 years (range: 18-55, $\mathrm{SD}=8.6 ; 37$ years for males, 33 years for females, ns). Death occurred on average 51.4 months (range: $3-122, \mathrm{SD}=33.5$ ) after entering index treatment; 52.3 months (range: $3-122, \mathrm{SD}=33.5$ ) for males and 44.5 months (range: 5-93, $\mathrm{SD}=34.4$ ) for females $(\mathrm{ns})$.

\begin{tabular}{|l|l|}
\hline Men & $68 \%$ \\
\hline Women & $32 \%$ \\
\hline Ethnic Norwegian & $94 \%$ \\
\hline Age, mean & $\begin{array}{l}31 \text { years (SD=8.1; range: 14-54 } \\
\text { yrs) }\end{array}$ \\
\hline Never married & $79 \%$ \\
\hline One or more children & $44 \%$ \\
\hline Daily care of children & $8 \%$ \\
\hline Stable accommodation & $48 \%$ \\
\hline $\begin{array}{l}\text { Unstable accommodation, last } 6 \text { months } \\
\text { (prison, in-patient treatment, family, } \\
\text { friends) }\end{array}$ & $52 \%$ \\
\hline Only completed primary school & $71 \%$ \\
\hline Income/support last 30 days & $17 \%$ \\
\hline Full/part time work & $58 \%$ \\
\hline Social security & $24 \%$ \\
\hline Disability pension/rehabilitation & $67 \%$ \\
\hline Drug sales/criminality & \\
\hline
\end{tabular}

Table 1: Sociodemographic characteristics for the total sample at intake to index treatment $(\mathrm{n}=481)$

\section{Main causes of death}

Overdose-related mortality was the most common specific cause of death for $68 \%$ of the sample. Fifteen percent died what was recorded as a "violent death" (traffic accidents, drowning, suicide, homicide, etc.), two persons died from AIDS/HIV and one from hepatitis C. Six cases were registered with uncertain/unknown cause of death, but all of them had toxicological findings from poly drug use. Nine out of ten women died from overdose. Forty-one out of 64 men (64\%) died from a drug overdose.

\section{Sample characteristics at intake to index treatment}

Sociodemographic characteristics are shown in Table 1. Sixty-eight percent of the sample was male and the mean age at treatment intake was 31 years ( $\mathrm{SD}=8.1$; range: $14-54 \mathrm{yrs}$ ). During life time $73 \%$ had used heroin for one year or more, $75 \%$ had used amphetamines and $83 \%$ had been injecting for a year or more. During the last 30 days before intake to treatment, $62 \%$ had used heroin, 34\% amphetamines $(69 \%$ had injected), $51 \%$ benzodiazepines, and $18 \%$ reported alcohol abuse (According to EuropASI alcohol abuse is defined as use of alcohol at least 3 days per week, with five or more alcoholic units a day, or twodays binge drinking, making daily functioning difficult). At baseline $59 \%$ reported one or more nonfatal overdoses throughout life, the mean number were four (median=1) $(\mathrm{SD}=9.3$, range: $0-9)$. Forty-two percent reported one or more suicide attempts in total life (mean: 1.3, $\mathrm{SD}=2.9$, range: $0-3.5$ ). The correlation between number of nonfatal overdoses and number of years injecting was 0.44 , while the correlation between nonfatal overdoses and suicide attempts was 0.28.

Fifty percent were cases on GSI as measured by SCL-25, and $75 \%$ had one or more personality disorders according to MCMI-II. Sixtyone percent reported having previously been in inpatient treatment one or more times in their lives, and the mean number of months in prison was 13 ( $\mathrm{SD}=23.0$, range: $0-99)$ (When the number reported was higher than 100 we consequently used 99 as a symbol (12 persons reported having been in prison more than 100 months)).

Men were on average three years older than the women (32 vs. 29 yrs, $\mathrm{p}<0.001)$, they had spent more time in prison (17 months vs. 5 months, $\mathrm{p}<0.001$ ), and they had higher scores on MCMI antisocial PD than the females ( 89 vs. $84 ; \mathrm{p}<0.05$ ). The males also had higher scores on MCMI alcohol dependence (76 vs. $68, \mathrm{p}<0.001$ ) and MCMI drug dependence ( 88 vs. $84, \mathrm{p}<0.05$ ) than the females. Females had used more benzodiazepines than the males the last month before the baseline interview (11 vs 9 days) $(\mathrm{p}<0.05)$, and they had higher scores on MCMI histrionic PD than the males ( 80 vs. 67, $\mathrm{p}<0.001$ ). There were no gender differences in the depression or anxiety scores as measured by HSCL- 25 .

\section{Differences between deceased and non-deceased patients at intake to treatment}

Table 2 indicates that the patients who died in the course of the study (deceased patients) were somewhat older than the ones who survived (non-deceased) at intake to treatment ( 32 vs. $30 \mathrm{yrs}$ ), they had more years with alcohol abuse before index treatment ( 7.8 vs. 5.3 , $\mathrm{p}<0.05$ ), they had had more nonfatal overdoses (5.9 vs. 3.6, $\mathrm{p}<0.05$ ), and they had spent more time in prison than the non-deceased clients (19 vs. 12 months, $\mathrm{p}<0.05$ ) (table 2). There was also a tendency for the deceased patients to have higher scores on MCMI antisocial PD than the non-deceased patients ( 91 vs. $86, p=0.07$ ). There were no differences in injecting drug use between deceased and non-deceased patients.

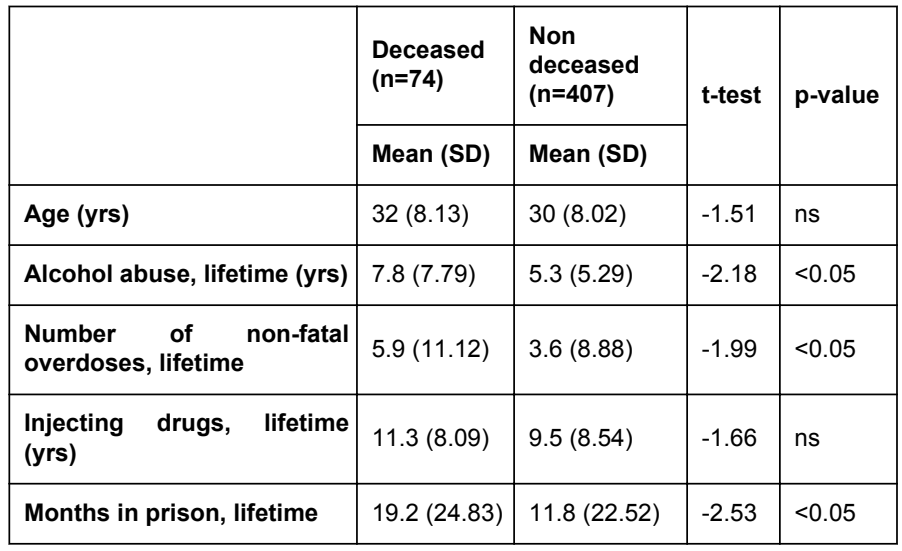

Table 2: Differences in background characteristics before index treatment between deceased and non-deceased clients.

Except for the patients in opiate maintenance treatment (OMT) $(n=74) 41 \%$ of the total sample completed their index treatment programme. The retention rate in OMT after ten years was 58\%. There 
were no significant gender differences in dropout rates from any treatment modality. Deceased patients were more likely to have dropped out of index treatment than non- deceased patients (64\% vs. $55 \%$, chi-square $31.43, \mathrm{p}<0.001$ ).

\section{Patient characteristics and treatment variables as predictors of mortality}

According to table 3, the strongest predictor of mortality was gender; males had 2.8 times greater chances than females of dying prematurely $(\mathrm{p}<0.01)$ (Table 2$)$. Also spending a total of more than one year in prison before intake to index treatment increased the chances of early death compared to those who had been incarcerated less $(\mathrm{p}<0.05)$. Likewise, having several nonfatal overdoses before index treatment portended mortality more frequently as compared to those with no or fewer nonfatal overdoses $(\mathrm{p}<0.05)$. In addition, patients who dropped out of index treatment had more chances of dying during the observation period than patients who completed $(\mathrm{p}<0.05)$ the period. In a further regression model, where the variable time in treatment was included in the analysis instead of dropout, the treatment variable was not significant. The correlation between dropout and time in index treatment was 0.48 (Pearson's r).

\begin{tabular}{|l|l|l|l|l|l|}
\hline & Beta & SE & p-value & Exp (B) & Cl (95\%) \\
\hline Gender & 1.02 & 0.35 & $<0.01$ & 2.77 & $1.39-5.51$ \\
\hline Age & -0.01 & 0.17 & $\mathrm{~ns}$ & 0.99 & $0.96-1.03$ \\
\hline $\begin{array}{l}\text { Non-fatal overdoses } \\
\text { (yes-no) }\end{array}$ & 0.58 & 0.28 & $<0.05$ & 1.79 & $1.04-3.07$ \\
\hline $\begin{array}{l}\text { No use of syringes } \\
\text { (last 30 days) }\end{array}$ & 0.05 & 0.33 & $\mathrm{~ns}$ & 1.05 & $0.55-2.00$ \\
\hline $\begin{array}{l}\text { Use of syringes } \\
\text { (1-29 days) }\end{array}$ & -0.07 & 0.32 & $\mathrm{~ns}$ & 0.94 & $0.50-1.76$ \\
\hline $\begin{array}{l}\text { Use of syringes } \\
\text { (all last 30 days) }\end{array}$ & 0.59 & 0.26 & $<0.05$ & 1.80 & $1.09-2.97$ \\
\hline $\begin{array}{l}\text { Prison > 12 months } \\
\text { (yes-no) }\end{array}$ & 0.42 & 0.25 & $=0.09$ & 1.52 & $0.93-2.48$ \\
\hline $\begin{array}{l}\text { Alcohol abuse } \\
\text { >5 yrs (yes-no) }\end{array}$ & 0.57 & 0.26 & $<0.05$ & 1.77 & $1.06-2.98$ \\
\hline $\begin{array}{l}\text { Dropout } \\
\text { (yes-no) }\end{array}$ & & & & \\
\hline
\end{tabular}

Table 3: Client characteristics before admission to treatment and dropout as predictors of mortality, Cox regression analyses $(n=481)$.

\section{Discussion}

Fifteen percent of the drug users in the study died during the 10 years after admission to index treatment. This represents an annual mortality rate of 1.5: 2.0 for males and 0.6 for females. The main cause of death was overdose $(68 \%)$. Being a male was by far the strongest predictor of all causes of mortality, but previous nonfatal overdoses, time in prison before baseline, as well dropout from index treatment were also related to increased mortality. A mortality rate of 1.5 is in line with most studies from Europe, which show mortality rates in the range of $1-2 \%$ per year among problem drug users.
As in other studies, the mortality rate among men was higher than among the women $[1,2,4,9,10,15,26]$. The relative risk of mortality among the male drug abusers was 12 times higher compared to the age-adjusted general Norwegian male population [27]. The corresponding number among the females was six times higher compared to the age-adjusted general female population [27]. Males in the general population also have about twice the age-adjusted mortality risk as females [27]. This difference in mortality between males and females underscores the importance of getting more gender specific knowledge about mortality in order to implement preventive measures especially tailored to address the specific needs of men and women.

The main cause of death was overdoses $(68 \%)$, which is consistent with other studies $[1,2,4,10,26]$. The majority died from heroin overdose but these deaths were also characterised by poly drug intoxications. Somewhat surprisingly, all but one of the women died from overdoses (90\%) compared to $59 \%$ of the men. It seems that contrasting findings in studies of female drug abusers may be due to different designs, populations and data collected, even within the same country $[10,28,29]$. The deceased females were on average four years younger than the males at time of death, they used less heroin than the males all through the observation period and fewer entered OMT. However, like the males they had a typical poly drug use, but with more use of benzodiazepines at index treatment. Autopsies of drug related deaths indicate that in many cases levels of heroin/morphine was low, but that poly drug use was common [30]. The lack of association between fatal overdose and injecting drug use may be a consequence of the high percentage of injection users in the sample (83\%).

Fifteen percent, and only males, died from what was classified as a violent death (traffic accidents, drowning, suicide, homicide etc.). Similar findings have been reported in other studies $[2,4,10,28]$. In all these cases the use of other substances was also found. Only two persons died from AIDS, which is consistent with findings in countries with a low prevalence of HIV/AIDS [5].

Time in prison prior to index treatment was a significant predictor of death after discharge from treatment. One possible explanation of this finding may be that this group of males was more antisocial and prone to taking risks, and both of these factors could lead to more crime and a more reckless lifestyle, including death by overdose. Even if MCMI antisocial PD was not a significant predictor of death in the regression analysis, there was a tendency for the deceased patients to have had higher scores on MCMI antisocial than the non-deceased clients. This finding is in line with another Norwegian study of drug users in which male gender, antisocial PD, and time in prison were related to death five years later [26]. Important preventive strategies for males should therefore be tailored especially to antisocial males with a criminal record, as opposed to females who seem to have another personality style and more use of benzodiazepines. However, we need more knowledge about overdoses among females to indicate gender specific preventive strategies.

Having had one or more nonfatal overdoses before index treatment was also associated with death. This corresponds with the findings from the three-year follow-up Australian Treatment Outcome Study (ATOS), where previous nonfatal overdose experience was related to subsequent nonfatal overdoses [31]. Having a history of nonfatal overdoses may also be associated with living a more reckless life. 
In the present study the association between number of lifethreatening overdoses and number of suicide attempts was not high, and in line with another prospective Norwegian treatment study of drug abusers, demonstrating that overdoses and suicide attempts may be distinguished on the basis of their disparate psychopathological risk variables and their different relationships to substances [17]. Screening for both previous overdose experience and suicide attempts is advised to identify drug users who are at risk of overdoses and/or suicide attempts.

Patients who completed treatment had a lower risk of dying during the 10 year follow-up. Patients who stay in treatment for prolonged time have better outcomes than patients who drop out or spend less time in treatment [26,32-35]. The first weeks after leaving inpatient treatment, when drug tolerance is low, comprise a critical period. Preventive strategies should therefore be specially tailored towards patients who leave treatment prematurely as well as towards patients at treatment completion.

The deceased patients reported more alcohol abuse prior to index treatment, and abuse of alcohol for more than five years before baseline was close to being a significant predictor of death $(\mathrm{p}=0.09)$. This tendency is consistent with other studies showing an association between abuse of alcohol and overdoses $[4,15,36]$. However, only $18 \%$ in our total sample reported alcohol abuse before index treatment. In a recent Norwegian study of drug-induced deaths, alcohol was found in only $15 \%$ of the cases, whereas the most common combination of drugs was heroin and benzodiazepines (50\%) [10]. Whereas most Norwegian heroin injectors also use benzodiazepines, less than half reported combined use with alcohol [29]. Our findings probably mirror the Norwegian pattern of drug use, with a high prevalence of heroin injection and poly drug use, often including a frequent use of benzodiazepines, but less use of alcohol.

As for preventive measures, there are no easy solutions at hand. The behavior of heroin users is often difficult to change. Those who may be in most need of organized treatment for their drug dependence as well as their other mental health disorders, may also be the ones who live under the most marginalized conditions and despair, and thus may both be difficult to reach and to keep in a rehabilitation process. A qualitative study of experiences with overdoses among Swedish heroin users is instructive in this context. The participants were aware of many of the common risk factors for overdoses. In spite of this, most overdoses occurred as a result of conscious risk-taking behavior. Search for the 'ultimate rush', as well as severe abstinence, anxiety and depression, feelings of indifference and dependency, and an unsafe, stressful environment were examples of factors that undermined the consideration of risks [16]. The authors conclude that heroin overdoses cannot be fully understood simply by defining a variety of isolated factors. It is more important to bolster understanding of how heroin users perceive and evaluate the risk they are taking, and what circumstances and which emotions and motives influence risk-taking that may lead to overdose.

Treatment providers and healthcare authorities are advised to further strengthen preventive strategies. Patients in treatment should take part as early as possible in overdose prevention awareness programs with particular emphasis on the nature of overdose risk in the event of their leaving treatment prematurely. Drug users also represent an overlooked potential workforce; they can be interested in and willing to attend preventive training courses and to apply such knowledge when necessary [37-39]. Programs to prevent fatal overdoses may be established and evaluated in the community, using resuscitation techniques as well as opioid antagonist medication such as naloxone [37,40-42]. Preliminary results indicate lifesaving events through peer administration of naloxone $[37,43]$. This research is still a young but promising field.

Better cooperation and communication between the health and social services are needed to identify and address the individuals, who are at particular risk, especially those characterized with multiple risk factors [10]. Preventive strategies must be planned and carried out in treatment and community settings alike, and in continuous cooperation between active users of heroin, clients in treatment, the families of heroin users, and healthcare and social service authorities. Outreach strategies should also be implemented to minimize destructive life-style patterns by crisis interventions and the use of low-threshold measures [44]. A wide range of preventive strategies is required if overdose deaths are to be reduced. Only a broad cooperation between all involved parties can help ensure that fewer heroin users, old and young alike, die from accidental or planned overdoses.

\section{Limitations and strengths}

Factors leading to overdoses and death are complex. In this study we have analyzed patient characteristics and treatment dropout as predictors, knowing that other factors may be associated with premature deaths. Also, all reports were self-reports and some bias in data is possible. The strength of the study lies in the prospective design and the length of the study period. Few studies of mortality among drug abusers have been able to follow a cohort of patients over a period of ten years.

\section{Conclusions}

The annual mortality rate in this study was 1.5 , which is in line with similar studies from Europe. The mortality rate was by far the highest among the men, and the main cause of death was overdoses. The deceased females were on average four years younger than the males at time of death, they used less heroin than the males all through the observation period, fewer entered OMT, and all died from overdoses. Male gender, lengthy time in prison prior to index treatment, having had several overdoses prior to index treatment and dropout from index treatment were all independent and significant predictors of premature death. Outreach strategies should be implemented to minimize destructive life-style patterns by crisis interventions and the use of low-threshold measures. A wide range of preventive strategies is required if overdose deaths are to be reduced.

\section{References}

1. Degenhardt L, Bucello C, Mathers B, Briegleb C, Ali H, et al. (2011) Mortality among regular or dependent users of heroin and other opioids: a systematic review and meta-analysis of cohort studies. Addiction 106: 32-51.

2. Clausen T, Anchersen K, Waal H (2008) Mortality prior to, during and after opioid maintenance treatment (OMT): a national prospective crossregistry study. Drug Alcohol Depend 94: 151-157.

3. Davoli M, Bargagli AM, Perucci CA, Schifano P, Belleudi V, et al. (2007) Risk of fatal overdose during and after specialist drug treatment: the VEdeTTE study, a national multi-site prospective cohort study. Addiction 102: 1954-1959.

4. Gossop M, Stewart D, Treacy S, Marsden J (2002) A prospective study of mortality among drug misusers during a 4-year period after seeking treatment. Addiction 97: 39-47. 
5. European Monitoring Centre for Drugs and Drug Addiction (EMCDDA) (2011) Mortality related to drug use in Europe: public health implications.

6. Bird SM, Robertson JR (2011) Toxicology of Scotlands drugs-related deaths in 2000-2007: presence of heroin, methadone, diazepam and alcohol by sex, age-group and era. Addict Res Theory 19: 170-178.

7. Hickman M, Carrivick S, Paterson S, Hunt N, Zador D, et al. (2007) London audit of drug-related overdose deaths: characteristics and typology, and implications for prevention and monitoring. Addiction 102: 317-323

8. Stoové MA, Dietze PM, Jolley D (2009) Overdose deaths following previous non-fatal heroin overdose: record linkage of ambulance attendance and death registry data. Drug Alcohol Rev 28: 347-352.

9. Ødegård E, Amundsen EJ, Kielland KB (2007) Fatal overdoses and deaths by other causes in a cohort of Norwegian drug abusers--a competing risk approach. Drug Alcohol Depend 89: 176-182.

10. Gjersing L, Jonassen KV, Biong S, Ravndal E, Waal H, et al. (2013) Diversity in causes and characteristics of drug-induced deaths in an urban setting. Scand J Public Health 41: 119-125.

11. McGregor C, Ali R, Lokan R, Christie P, Darke S (2002) Accidental fatalities among heroin users in South Australia, 1994-1997: toxicological findings and circumstances of death. Addict Res \& Theory 10: 335-346.

12. Merrall EL, Kariminia A, Binswanger IA, Hobbs MS, Farrell M, et al. (2010) Meta-analysis of drug-related deaths soon after release from prison. Addiction 105: 1545-1554.

13. Ravndal E, Amundsen EJ (2010) Mortality among drug users after discharge from inpatient treatment: an 8-year prospective study. Drug Alcohol Depend 108: 65-69.

14. Ã degrd E, Amundsen EJ, Kielland KB, Kristoffersen R (2009) The contribution of imprisonment and release to fatal overdose and unnatural death among a cohort of Norwegian drug abusers. Addict Res Theory.

15. Darke S, Degenhardt L, Mattick R (2007) Mortality Amongst Illicit Drug Users. Cambridge University Press, Cambridge.

16. Richert T, Svensson B (2008) Med livet som innsats "injeksjonsmissbruk, risktagande och verdoser (With your life on the line - injecting, risktaking and overdoses). Nor J Alcohol Drugs 25: 355-376.

17. Ravndal E, Vaglum P (1999) Overdoses and suicide attempts: different relations to psychopathology and substance abuse? A 5-year prospective study of drug abusers. Eur Addict Res 5: 63-70.

18. www.sirus.no Substance used related deaths in Norway 2012. Newsletter 06.01.14, Norwegian Institute for Alcohol and Drug Research, Oslo, 2014.

19. Møller LF, Matic S, van den Bergh BJ, Moloney K, Hayton P, et al. (2010) Acute drug-related mortality of people recently released from prisons. Public Health 124: 637-639.

20. Farrell M, Marsden J (2008) Acute risk of drug-related death among newly released prisoners in England and Wales. Addiction 103: 251-255.

21. Lauritzen G, Ravndal E, Larsson J (2012). Gjennom 10 r. En oppf, lgingsstudie av narkotikabrukere i behandling (Through 10 years. A prospective follow-up study of drug users in treatment). SIRUS report no. 6, The Norwegian Institute for Alcohol and Drug Research, Oslo.

22. Kokkevi A, Hartgers C (1994) European Addiction Severity Index EuropASI, Cost A6.

23. Derogatis LR, Lipman RS, Rickels K, Uhlenhuth EH, Covi L (1974) The Hopkins Symptom Checklist (HSCL): a self-report symptom inventory. Behav Sci 19: 1-15.

24. Millon T (1987) Millon Clinical Multiaxial Inventory-II. National Computer Systems, MinnÂAeapolis.

25. McLellan AT, Luborsky L, Woody GE, O'Brien CP (1980) An improved diagnostic evaluation instrument for substance abuse patients. The Addiction Severity Index. J Nerv Ment Dis 168: 26-33.
26. Ravndal E, Vaglum P (1998) Psychopathology, treatment completion and 5 years outcome. A prospective study of drug abusers. J Subst Abuse Treat 15: 135-142.

27. Statistics Norway (2013) Causes of death. http://www. ssb.no.dodsarsak. Access date: 10.11 .13

28. Gjersing L, Bretteville-Jensen AL (2014) Gender differences in mortality and risk factors in a 13-year cohort study of street-recruited injecting drug users. BMC Public Health 14: 440.

29. Bretteville-Jensen AL (2005) A konomiske aspekter ved sprÃ ,ytemisbrukeres forbruk vrusmidler (Economical aspects in regards to injecting drug users substance use). SIRUS report no. 4, Oslo.

30. Teige B (1998) Narkotikad Ã, dsfall - epidemiologi (Drug related deaths epidemiology). Rettsmedisin 3: 63-65.

31. Darke S, Williamson A, Ross J, Mills KL, Havard A, et al. (2007) Patterns of nonfatal heroin overdose over a 3-year period: findings from the Australian treatment outcome study. J Urban Health 84: 283-291.

32. De Leon G, Sacks S, Staines G, McKendrick K (2000) Modified therapeutic community for homeless mentally ill chemical abusers: treatment outcomes. Am J Drug Alcohol Abuse 26: 461-480.

33. Simpson DD, Joe GW, Brown BS (1997) Treatment retention and followup outcomes in the Drug Abuse Treatment Outcome Study (DATOS). Psychol Addict Behav 11: 294-307.

34. Simpson DD, Joe GW, Rowan-Szal GA (1997) Drug abuse treatment retention and process effects on follow-up outcomes. Drug Alcohol Depend 47: 227-235.

35. Kooyman M (1992) Therapeutic Community for Addicts: Intimacy, Parent Involvement and Treatment Outcome. Erasmus Universiteit, Rotterdam.

36. Joe GW, Simpson DD (1990) Death rates and risk factors; in: Simpson DD, Sells SB (eds): Opioid Addiction and Treatment: a 12-Year Followup. Kruger, Malabar, Florida.

37. Strang J, Manning V, Mayet S, Best D, Titherington E, et al. (2008) Overdose training and take-home naloxone for opiate users: prospective cohort study of impact on knowledge and attitudes and subsequent management of overdoses. Addiction 103: 1648-1657.

38. Baca CT, Grant KJ (2007) What heroin users tell us about overdose. J Addict Dis 26: 63-68.

39. Lagu T, Anderson BJ, Stein M (2006) Overdoses among friends: drug users are willing to administer naloxone to others. J Subst Abuse Treat 30: 129-133.

40. Piper TM, Rudenstine S, Stancliff S, Sherman S, Nandi V, et al. (2007) Overdose prevention for injection drug users: lessons learned from naloxone training and distribution programs in New York City. Harm Reduct J 4: 3.

41. Galea S, Worthington N, Piper TM, Nandi VV, Curtis M, et al. (2006) Provision of naloxone to injection drug users as an overdose prevention strategy: early evidence from a pilot study in New York City. Addict Behav 31: 907-912.

42. Dettmer K, Saunders B, Strang J (2001) Take home naloxone and the prevention of deaths from opiate overdose: two pilot schemes. BMJ 322 895-896.

43. Seal KH, Thawley R, Gee L, Bamberger J, Kral AH, et al. (2005) Naloxone distribution and cardiopulmonary resuscitation training for injection drug users to prevent heroin overdose death: a pilot intervention study. J Urban Health 82: 303-311.

44. Marshall BDL, Milloy MJ, Wood E, Montaner JSG, Kerr T (2011) Reduction in overdose mortality after the opening of North Americas first medically supervised safer injecting facility: a retrospective population-based study. Lancet 377: 1429-1437. 